\title{
Efficacy of olmesartan amlodipine in Colombian hypertensive patients (soat study)
}

\author{
Richard Buendia ${ }^{1 *}$ (D) and Monica Zambrano²
}

\begin{abstract}
Background: Emerging evidence has shown a significant deficit in the control of hypertension (blood pressure $<140 / 90 \mathrm{mmHg}$ ) among Hispanics or Latinos in about $65 \%$. This study aims to determine the efficacy of the combination in fixed doses of olmesartan and amlodipine $(20 / 5,40 / 5$, and $40 / 10 \mathrm{mg})$ in hypertensive patients treated in daily clinical practice by Colombian doctors.

Methods: This was an observational, retrospective, open-label, multi-center, non-comparative study. The primary outcome was a change in systolic and diastolic blood pressure from the baseline to week 12; the secondary outcome was the proportion of patients achieving a target blood pressure of $<140 / 90 \mathrm{mmHg}$. Safety and tolerability were also evaluated. For analysis, a student $t$ test was used for paired data, McNemar test, and ANCOVA.

Results: A total of 428 patients were enrolled from 16 centers in Colombia. At 12 weeks, patients'systolic blood pressure decreased in response to all three doses: by $27.75 \pm 20.73 \mathrm{mmHg}$ in $20 / 5 \mathrm{mg}, 31.13 \pm 22.23 \mathrm{mmHg}$ in $40 / 5 \mathrm{mg}$, and $46.96 \pm 20.15 \mathrm{mmHg}$ in $40 / 10 \mathrm{mg}$ (all $\mathrm{p}<0.001$ ). Furthermore, the diastolic blood pressure decreased by $14.19 \pm 12.89 \mathrm{mmHg}$ in $20 / 5 \mathrm{mg}, 16.25 \pm 10.87 \mathrm{mmHg}$ in $40 / 5 \mathrm{mg}$, and $24.83 \pm 10.41 \mathrm{mmHg}$ in $40 / 10 \mathrm{mg}$ (all $\mathrm{p}<0.001$ ). The percentage of patients achieving target blood pressure was $71.31 \%$ in $20 / 5 \mathrm{mg}, 70.16 \%$ in $40 / 5 \mathrm{mg}$, and $63.33 \%$ in $40 / 10 \mathrm{mg}$.
\end{abstract}

Conclusions: This study demonstrates the efficacy of the combination in fixed doses of olmesartan and amlodipine in the treatment of Colombian hypertensive patients.

Keywords: Olmesartan, Amlodipine, Practice patterns

\section{Background}

Hypertension is a highly prevalent disease that ranges from 30 to $44 \%$ and remains under diagnosed and undertreated [1-3]. Highly effective therapies are therefore required to avoid complications in target organs such as the retina, kidney, brain, and heart. Emerging data seem to suggest that Hispanics might have rates of uncontrolled hypertension that significantly exceed the rates observed in non-Hispanic people [4]. The Hispanic Community Health Study/Study of Latinos is a longitudinal cohort study of 16,415 Hispanics/Latinos. This study shows a significant deficit in the control of hypertension

\footnotetext{
*Correspondence: pernoll@gmail.com

${ }^{1}$ Colsubsidio Centro de Especialistas, Pontificia Universidad Javeriana, Hospital de la Policía, Bogotá, D.C., Colombia

Full list of author information is available at the end of the article
}

(blood pressure $<140 / 90 \mathrm{mmHg}$ ) among Hispanics/Latinos in about $65 \%$ [5]. The combination of olmesartan and amlodipine in fixed doses (FDC) could be an effective choice for the management of hypertension in Hispanic patients. This study aims to determine the efficacy of the combination of olmesartan and amlodipine FDC in Colombian hypertensive patients for the reduction of systolic and diastolic blood pressure values; it also aims to determine the adverse effects associated with such treatment.

\section{Methods}

This study was an observational, open-label, retrospective, multi-center, non-comparative clinical study with a total treatment period of 12 weeks, conducted at 16 clinical sites in Colombia. The cities included in the study were Barranquilla, Santa Marta, Cartagena, Monteria, 
Valledupar, Medellín, Bucaramanga, Cúcuta, Bogotá, Villavicencio, Ibagué, Neiva, Cali, Pereira, Armenia, and Ipiales.

The sample size was calculated seeking a reduction of $20 \mathrm{mmHg}$ of systolic blood pressure (SBP) and $10 \mathrm{mmHg}$ of diastolic blood pressure (DBP) with the use of olmesartan and amlodipine, with a $\mathrm{p}$ value $<0.05$ and a power of $80 \%$, resulting in at least 246 patients.

The inclusion criteria encompassed patients over 18 years old, untreated patients with uncontrolled hypertension $(\geq 140 / 90 \mathrm{mmHg})$, creatinine clearance $>60 \mathrm{ml} /$ min or creatinine $<1.3 \mathrm{mg} / \mathrm{dl}$, with or without other cardiovascular risk factors, who signed the informed consent and had no contraindication for the use of olmesartan and/or calcium antagonists.

The patients with any of these conditions such as: secondary hypertension, hypertensive emergency, or target organ damage such as heart failure, unstable angina, hypertensive encephalopathy, myocardial infarction, stroke, history of coronary revascularization, valvular heart disease, and serious arrhythmia. Patients with severe organ dysfunction, as assessed by laboratory abnormality, and pregnancy were excluded.

The blood pressure data was collected from the medical records of clinical sites and included baseline, 6 , and 12 weeks, according to the combination of olmesartan and amlodipine fixed doses of 20/5, 40/5, and 40/10 mg.

The data was processed by the analysis of paired observations, paired student t-test, and the McNemar test for categorical data analysis. The SBP and DBP at weeks 0,6 , and 12 were analyzed using the repeated-measures analysis of covariance (ANCOVA) with covariates of baseline SBP and DBP. Two-tailed p values of less than 0.05 were considered to be statistically significant. Statistical analyses were conducted by using STATA 12 (StataCorp).

The primary outcome was a change in SBP and DBP from the baseline to week 12 . The secondary outcome was the proportion of patients achieving a target blood pressure of $<140 / 90 \mathrm{mmHg}$. The reduction of pulse pressure (PP) was defined as the difference between systolic and diastolic pressure for each dose of olmesartan and amlodipine FDC.

The blood pressure (BP) was measured with mercury sphygmomanometers that were appropriate for each patient's anthropometric parameters, and both sides of the arms were measured. The BP used in the study was the mean of three measurements, which were performed after $10 \mathrm{~min}$ of rest in the seated position. The $\mathrm{BP}$ was read in $2 \mathrm{mmHg}$ intervals to prevent the risk of bias.

The study was conducted according to the Good Clinical Practice guidelines and the Declaration of Helsinki.

\section{Results}

A total of 428 patients were enrolled from 16 centers in Colombia. Of these patients, $46.96 \%$ were male, $3.27 \%$ were diabetic, $42.7 \%$ received olmesartan and amlodipine FDC $20 / 5 \mathrm{mg}, 46.2 \%$ received a dose of $40 / 5 \mathrm{mg}$, and $10.9 \%$ received a dose of $40 / 10 \mathrm{mg}$. The mean age was $61.35 \pm 12.72$ years; the SBP mean was $162.04 \pm 18.88 \mathrm{mmHg}$, and the DBP mean was $96.36 \pm 10.53 \mathrm{mmHg}$.

Patients with hypertension stage 1 accounted for $30.84 \%$ of the sample, while patients with hypertension stage 2 comprised $69.16 \%$, according to criteria of the Joint National Committee (JNC 8) [6] (see Table 1). The SBP at 6 weeks showed a statistically significant reduction from baseline values in all three groups of olmesar$\tan$ and amlodipine FDC. With a dose of $20 / 5 \mathrm{mg}$, the SBP was $18.76 \pm 21.72 \mathrm{mmHg}$; with a $40 / 5 \mathrm{mg}$ dose, SBP was $20.83 \pm 22.64 \mathrm{mmHg}$; and with a $40 / 10 \mathrm{mg}$ dose, SBP was $36.68 \pm 21.87 \mathrm{mmHg}$ (all p < 0.001). At 12 weeks, the SBP decreased in all three doses: by $27.75 \pm 20.73 \mathrm{mmHg}$ in $20 / 5 \mathrm{mg}, 31.13 \pm 22.23 \mathrm{mmHg}$ in $40 / 5 \mathrm{mg}$, and $46.96 \pm 20.15 \mathrm{mmHg}$ in $40 / 10 \mathrm{mg}$ (all $\mathrm{p}<0.001$ ). There were statistically significant differences between dose

\section{Table 1 Baseline characteristics}

\begin{tabular}{lcc}
\hline Category & N & $\%$ \\
\hline Sex & 201 & \\
Male & 227 & 46.96 \\
Female & 14 & 53.04 \\
Diabetes mellitus & 38 & 3.27 \\
Hyperlipidemia & & 8.88 \\
Olmesartan and amlodipine doses & 183 & \\
20/5 mg & 198 & 42.76 \\
40/5 mg & 47 & 46.26 \\
40/10 mg & & 10.98 \\
Hypertension stage & 132 & \\
Hypertension stage 1 & 296 & 30.84 \\
Hypertension stage 2 & Mean & 69.16 \\
\hline Numeric variables & 162.04 & SD \\
\hline Systolic blood pressure & 96.36 & 18.88 \\
Diastolic blood pressure & 65.67 & 10.53 \\
Pulse pressure & 61.35 & 16.81 \\
Age & 210.46 & 12.72 \\
Total Cholesterol mg/dl & 115.39 & 39.47 \\
LDL Cholesterol mg/dl & 47.04 & 41.06 \\
HDL Cholesterol mg/dl & 181.86 & 14.21 \\
Triglycerides mg/dl & 6.36 & 0.84 \\
Hemoglobin A1c \% & 0.9 & \\
Creatinine & & \\
\hline N & & \\
\hline
\end{tabular}

$\mathrm{N}=428$ patients 
groups 20/5 mg and 40/5 mg, p < 0.001; 20/5 mg and $40 / 10 \mathrm{mg}, \mathrm{p}=0.036$; however, there were no differences between the doses $40 / 5 \mathrm{mg}$ and $40 / 10 \mathrm{mg}, \mathrm{p}=1$ (see Table 2; Fig. 1).

The DBP values at 6 weeks also showed a statistically significant decrease from the baseline in all three groups of olmesartan and amdolipine FDC: with a 20/5 mg dose, DBP was $8.79 \pm 12.85 \mathrm{mmHg}$; with a $40 / 5 \mathrm{mg}$, DBP was $10.03 \pm 10.67 \mathrm{mmHg}$; and with a $40 / 10 \mathrm{mg}$ dose, DBP was $20.09 \pm 12.44 \mathrm{mmHg}$ (all $\mathrm{p}<0.001$ ). At 12 weeks, the reduction with a $20 / 5 \mathrm{mg}$ dose was $14.19 \pm 12.89 \mathrm{mmHg}$; with a $40 / 5 \mathrm{mg}$ dose, the reduction was $16.25 \pm 10.87 \mathrm{mmHg}$, and with a $40 / 10 \mathrm{mg}$, the reduction was $24.83 \pm 10.41 \mathrm{mmHg}$ (all $\mathrm{p}<0.001$ ). There was no difference between dose groups of $20 / 5$ and $40 / 5 \mathrm{mg}$ $(\mathrm{p}=0.95), 20 / 5 \mathrm{mg}$ and $40 / 10 \mathrm{mg}(\mathrm{p}=0.108)$, and $40 / 5 \mathrm{mg}$ and 40/10 mg ( $\mathrm{p}=0.33)$ (see Table 3; Fig 2).

The SBP mean of the diabetic patients was $153.36 \pm 32.24 \mathrm{mmHg}$ (range: 120-230) and in patients with dyslipidemia the SBP mean was $154.29 \pm 25.23 \mathrm{mmHg}$ (range: 70-230). The DBP mean in diabetic patients was $83.84 \pm 15.56 \mathrm{mmHg}$ (range: 60-120) and patients with dyslipidemia was $94.82 \pm 11.67 \mathrm{mmHg}$ (range 65-120).

The reduction in SBP in diabetic patients was $37.12 \mathrm{mmHg}(\mathrm{p}=0.072)$ at 6 weeks and $39.12 \mathrm{mmHg}$ $(\mathrm{p}=0.032)$ at 12 weeks. In hyperlipidemic patients SBP was reduced by $26.64 \mathrm{mmHg}(\mathrm{p}=0.45)$ at 6 weeks and $26.64 \mathrm{mmHg}(\mathrm{p}=0.89)$ at 12 weeks.

The reduction in DBP in diabetic patients was $16.43 \mathrm{mmHg}(\mathrm{p}=0.064)$ at 6 weeks and $24.83 \mathrm{mmHg}$ $(\mathrm{p}=0.001)$ at 12 weeks, in patients with hyperlipidemia DBP was reduced by $27.38 \mathrm{mmHg}(\mathrm{p}<0.001)$ at 6 weeks and $32.38 \mathrm{mmHg}(\mathrm{p}=0.002)$ at 12 weeks.

The dosage of olmesartan and amlodipine FDC prescribed in hypertension stage 1 was $43.71 \%$ in $20 / 5 \mathrm{mg}$, $22.23 \%$ in $40 / 5 \mathrm{mg}$, and $17.03 \%$ in $40 / 10 \mathrm{mg}$. In stage 2 , the dosage was $56.28 \%$ in $20 / 5 \mathrm{mg}, 77.78 \%$ in $40 / 5 \mathrm{mg}$, and $82.98 \%$ in $40 / 10 \mathrm{mg}$, these proportion of hypertensive patients stage 2 decrease statistically significant to

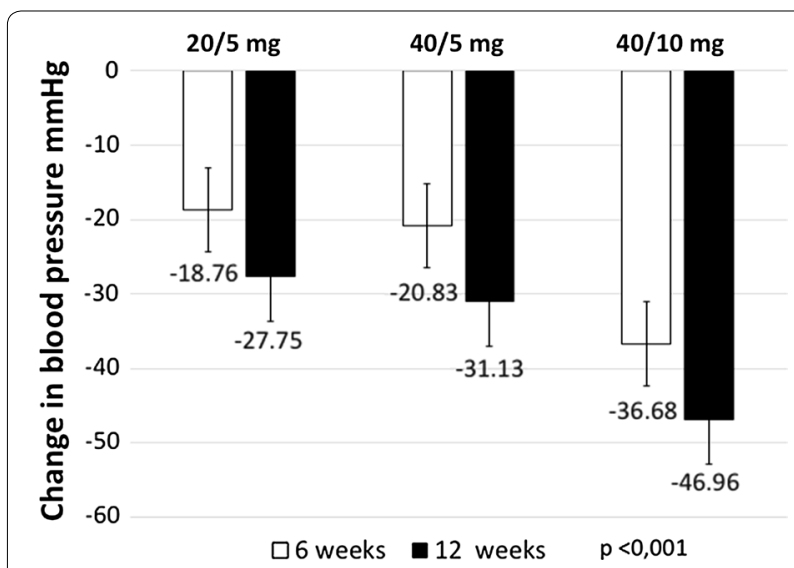

Fig. 1 Reduction of mean systolic blood pressure values at 6 and 12 weeks for each dose of olmesartan and amlodipine FDC

$1.64 \%$ with the dose of $20 / 5 \mathrm{mg}, 1.61 \%$ in $40 / 5 \mathrm{mg}$, and $0 \%$ in $40 / 10 \mathrm{mg}$ at 12 weeks of olmesartan and amlodipine FDC ( $<$ < 0.016) (Fig. 3).

The secondary outcome was the proportion of patients achieving a target BP of $<140 / 90 \mathrm{mmHg}$ (controlled). At 12 weeks, $71.31 \%$ of patients with a dose of $20 / 5 \mathrm{mg}$, $70.16 \%$ with a dose of $40 / 5 \mathrm{mg}$, and $63.33 \%$ with a dose of $40 / 10 \mathrm{mg}$ had achieved the target $(\mathrm{p}<0.016)$. There were no differences by sex $(\mathrm{p}=0.19)$ or among diabetic $(\mathrm{p}=0.625)$ or hyperlipidemic $(\mathrm{p}=0.203)$ patients (Fig. 3).

The pulse pressure at 12 weeks demonstrated a statistically significant reduction with each dose of olmesartan and amlodipine FDC. The dose of $20 / 5 \mathrm{mg}$ in $13.55 \pm 10.17 \mathrm{mmHg}$, with $40 / 5 \mathrm{mg}$ in $14.88 \pm 21.29 \mathrm{mmHg}$, and with $40 / 10 \mathrm{mg}$ in $22.13 \pm 16.78 \mathrm{mmHg}($ all $\mathrm{p}<0.001)($ see Table 4$)$.

There was no report of discontinuation of treatment with the use of olmesartan and amlodipine FDC for 12 weeks. The proportions of adverse effects were as follows: headache, 4 patients $(0.9 \%)$; dizziness, 5 patients (1.17\%); and peripheral edema; 3 patients $(0.7 \%)$.

Table 2 Reduction of mean systolic blood pressure values at 6 and 12 weeks for each dose of olmesartan and amlodipine FDC

\begin{tabular}{|c|c|c|c|c|c|c|c|}
\hline $\begin{array}{l}\text { Olmesartan } \\
\text { and amlodipine } \\
\text { doses }\end{array}$ & $\begin{array}{l}\text { Baseline } \\
(\text { mean } \pm \text { SD) }\end{array}$ & $\begin{array}{l}6 \text { weeks } \\
(\text { mean } \pm \text { SD) }\end{array}$ & $\begin{array}{l}\text { Difference } \\
\text { initial/6 weeks } \\
\text { (mean } \pm \text { SD) }\end{array}$ & $p$ & $\begin{array}{l}12 \text { weeks } \\
(\text { mean } \pm \text { SD) }\end{array}$ & $\begin{array}{l}\text { Difference } \\
\text { initial/12 weeks } \\
\text { (mean } \pm \text { SD) }\end{array}$ & $p$ \\
\hline $\begin{array}{l}20 / 5 \mathrm{mg}(\mathrm{N}=183 \\
\text { patients) }\end{array}$ & $157 \pm 16.28$ & $138.45 \pm 14.10$ & $18.76 \pm 21.72$ & $<0.001$ & $129.24 \pm 12.92$ & $27.75 \pm 20.73$ & $<0.001$ \\
\hline $\begin{array}{l}40 / 5 \mathrm{mg}(\mathrm{N}=198 \\
\text { patients) }\end{array}$ & $161.93 \pm 17.92$ & $140.85 \pm 14.04$ & $20.83 \pm 22.64$ & $<0.001$ & $130.79 \pm 10.77$ & $31.13 \pm 22.23$ & $<0.001$ \\
\hline $\begin{array}{l}40 / 10 \mathrm{mg}(\mathrm{N}=47 \\
\text { patients) }\end{array}$ & $176.46 \pm 18.68$ & $140 \pm 12.88$ & $36.68 \pm 21.87$ & $<0.001$ & $129.5 \pm 12.40$ & $46.96 \pm 20.15$ & $<0.001$ \\
\hline
\end{tabular}


Table 3 Reduction of mean diastolic blood pressure values at 6 and 12 weeks for each dose of olmesartan and amlodipine FDC

\begin{tabular}{|c|c|c|c|c|c|c|c|}
\hline $\begin{array}{l}\text { Olmesartan } \\
\text { and amlodipine } \\
\text { doses }\end{array}$ & $\begin{array}{l}\text { Baseline } \\
(\text { mean } \pm \text { SD) }\end{array}$ & $\begin{array}{l}6 \text { weeks } \\
(\text { mean } \pm \text { SD) }\end{array}$ & $\begin{array}{l}\text { Difference } \\
\text { initial/6 weeks } \\
\text { (mean } \pm \text { SD) }\end{array}$ & $p$ & $\begin{array}{l}12 \text { weeks } \\
\text { (mean } \pm \text { SD) }\end{array}$ & $\begin{array}{l}\text { Difference } \\
\text { initial/12 weeks } \\
(\text { mean } \pm \text { SD) }\end{array}$ & $p$ \\
\hline $\begin{array}{l}20 / 5 \mathrm{mg}(\mathrm{N}=183 \\
\text { patients })\end{array}$ & $93.44 \pm 10.20$ & $84.76 \pm 7.79$ & $8.79 \pm 12.85$ & $<0.001$ & $79.24 \pm 7.89$ & $14.19 \pm 12.89$ & $<0.001$ \\
\hline $\begin{array}{l}40 / 5 \mathrm{mg}(\mathrm{N}=198 \\
\text { patients })\end{array}$ & $96.91 \pm 7.98$ & $86.68 \pm 8.72$ & $10.03 \pm 10.67$ & $<0.001$ & $80.66 \pm 6.67$ & $16.25 \pm 10.87$ & $<0.001$ \\
\hline $\begin{array}{l}40 / 10 \mathrm{mg}(\mathrm{N}=47 \\
\text { patients) }\end{array}$ & $103.26 \pm 7.77$ & $83.59 \pm 8.22$ & $20.09 \pm 12.44$ & $<0.001$ & $78.43 \pm 6.07$ & $24.83 \pm 10.41$ & $<0.001$ \\
\hline
\end{tabular}

$\mathrm{N}=428$ patients

\section{Discussion}

In this 12 week study, we found that the olmesartan and amlodipine FDC was effective in controlling systolic and diastolic BP in clinical practice for Colombian patients. There was a statistically significant reduction in systolic blood pressure values after 6 weeks of treatment, between 18 and $36 \mathrm{mmHg}$, depending on the dose received; the reduction after 12 weeks was between 26 and $47 \mathrm{mmHg}$. The diastolic blood pressure values were also reduced, between 8 and $20 \mathrm{mmHg}$ at 6 weeks and between 14 and $24 \mathrm{mmHg}$ at 12 weeks.

These results are higher than those found in pivotal studies such as the COACH study (The factorial Combination of olmesartan medoxomil and amlodipine besylate in Controlling High Blood Pressure)-a randomized, placebo-controlled study in which the efficiency of dual combination therapy with olmesartan and amlodipine was compared with its components in monotherapy. In patients with hypertension from mild to severe, reductions in SBP values were found between 23 and $30 \mathrm{mmHg}$; DBP values were reduced between 14 and $19 \mathrm{mmHg}$ [7]. Volpe et al. [8] conducted a randomized, multi-center, single-arm study of 755 patients with hypertension in monotherapy with amlodipine $5 \mathrm{mg} /$ day without response. They were then randomized to olmesartan and amlodipine FDC 20/5, 40/5, and 40/10 mg. The reduction in systolic and diastolic blood pressure values were found to be in the range of $16.8 \mathrm{mmHg}$ to 9.6 , respectively $(\mathrm{p}<0.0001)$. In the study BP-CRUSH [9] open-label, multi-center and single-arm, with olmesar$\tan$ and amlodipine plus hydrochlorothiazide if necessary to maintain a blood pressure of $120 / 70 \mathrm{mmHg}$-at 20 weeks, the study showed reductions in systolic blood pressure values between 14 and $20.3 \mathrm{mmHg}$ and in diastolic values between 7.7 and $11.3 \mathrm{mmHg}(\mathrm{p}<0.001)$.

In patients with diabetes and hyperlipidemia, there are interesting results in reducing blood pressure levels with the combination olmesartan and amlodipine FDC, although caution should be exercised in interpreting the

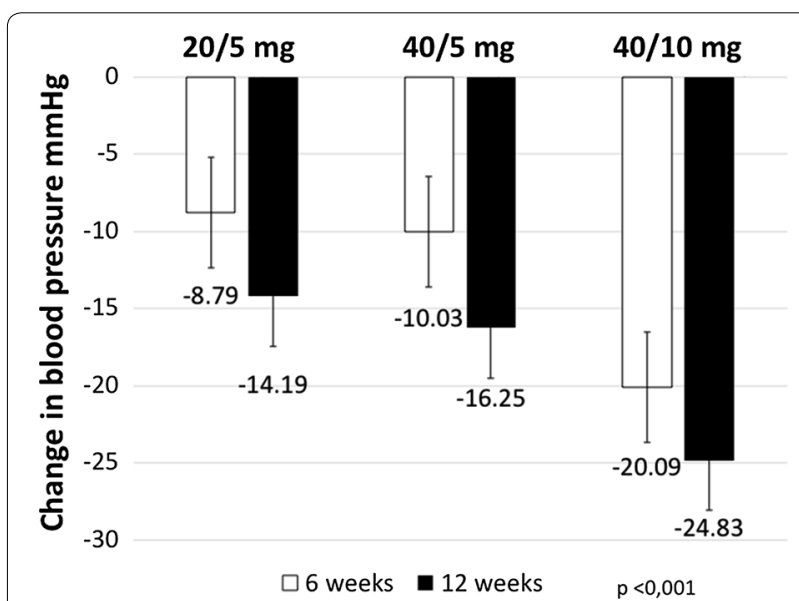

Fig. 2 Reduction of mean diastolic blood pressure values at 6 and 12 weeks for each dose of olmesartan and amlodipine FDC

results, because of the reduced proportion of patients with diabetes $(3.27 \%)$ and hyperlipidemia $(8.88 \%)$ in the study.

Interestingly, the dosage of olmesartan and amlodipine FDC prescribed was directly proportional to the stage of hypertension; for example, the dose of $40 / 10 \mathrm{mg}$ was prescribed more in stage 2, while a $20 / 5 \mathrm{mg}$ dose was prescribed in stage 1 . The proportion of hypertensive patients in stage 2 at the baseline (between 56.28 and 82.98, depending on the dose of olmesartan and amlodipine FDC) decreased statistically significant between 0 and $1.64 \%$ at 12 weeks $(\mathrm{p}<0.016)$, demonstrating a high antihypertensive efficacy of different doses of olmesartan and amlodipine FDC.

In the secondary outcome, this study showed a significant proportion of patients achieving their blood pressure goal $(<140 / 90 \mathrm{mmHg})$ with olmesartan and amlodipine FDC. Between 63 and $71 \%$ showed trends similar to previous studies such as $\mathrm{COACH}$ (between 42.5 and 51\%) [7] and BP-CRUSH (between 49 and 77\%) [9]. 


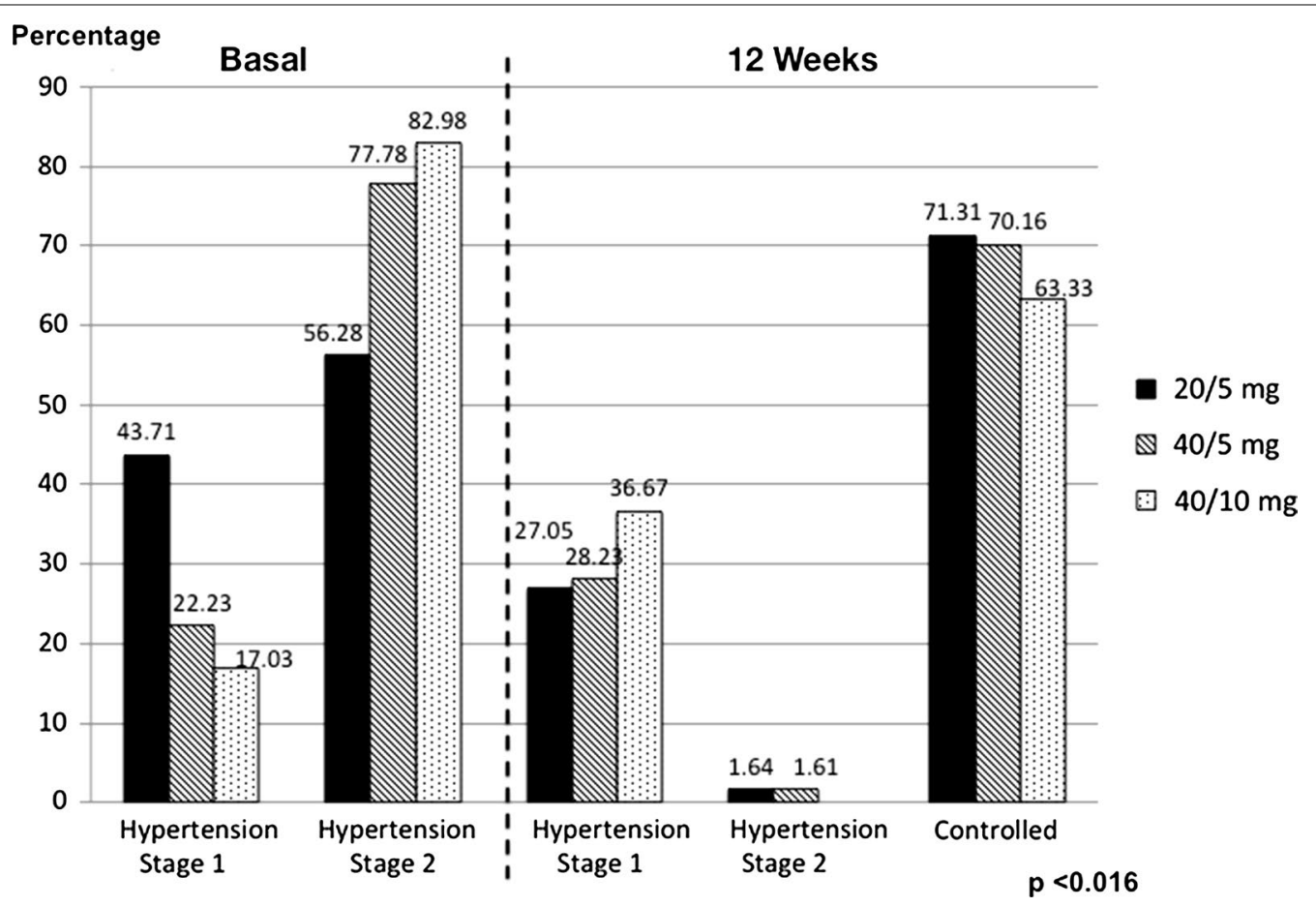

Fig. 3 Dosage prescribed of olmesartan and amlodipine FDC according to stage of hypertension, baseline and 12 weeks

Table 4 Reduction of mean pulse pressure values at 12 weeks for each dose of olmesartan and amlodipine FDC

\begin{tabular}{llcll}
\hline Olmesartan and amlodipine doses & Baseline (mean \pm SD) & 12 weeks (mean \pm SD) & Difference initial/12 weeks (mean \pm SD) & p \\
\hline $20 / 5 \mathrm{mg}(\mathrm{N}=183$ patients) & $63.55 \pm 15.57$ & $50 \pm 11.19$ & $13.55 \pm 18.84$ & $<0.001$ \\
$40 / 5 \mathrm{mg}(\mathrm{N}=198$ patients) & $65.01 \pm 16.92$ & $50.12 \pm 10.54$ & $14.88 \pm 21.29$ & $<0.001$ \\
$40 / 10 \mathrm{mg}(\mathrm{N}=47$ patients) & $73.2 \pm 17.09$ & $51.06 \pm 11.21$ & $22.13 \pm 16.78$ & $<0.001$ \\
\hline
\end{tabular}

$\mathrm{N}=428$ patients

Recently, it was found that Latin American patients with high pulse pressure are associated with 2.6 times more likely to have cardiovascular events [10], and in American patients pulse pressure has been associated with increased overall mortality causes and cardiovascular mortality, from 29 to 54\% [11]. A meta-analysis of 14 studies with 510.546 patients found that an increase in brachial pulse pressure of $10 \mathrm{mmHg}$ was associated with an increase of $13 \%$ in cardiovascular events and $9 \%$ in mortality [12].

This study found an important and significant reduction in pulse pressure of $13-22.13 \mathrm{mmHg}$. In the light of the evidence, this could reduce morbidity and mortality in our patients, but another type of study would be required to determine its effect.

Increased blood pressure is an important risk factor for stroke, heart disease, and kidney failure. Many clinical trials have shown that reducing the BP by a variety of strategies reduces the risk of stroke by about $35 \%$, congestive heart failure by $42 \%$, and coronary heart disease by 28\% [13-15]. The European guidelines for hypertension recommend a target SBP and DBP of $<140 / 90 \mathrm{mmHg}$ in the general population $[16,17]$. In these guidelines, blockers-angiotensin receptor and calcium channel blockers-are recommended as a first-line treatment, either as monotherapy or in combination.

The limitations of this study are mainly due to its retrospective, open-label design, short study duration, and the possible underreporting of adverse effects. The evidence has shown a range of adverse effects with olmesartan and amlodipine, such as edema (in $0.5 \%$ ), headache, and dizziness (in $1.6 \%$ on average) [8].

In Colombia, the prevalence of hypertension is $23 \%$, of which $59.8 \%$ are diagnosed, $36.3 \%$ are being treated and only $11.8 \%$ are correctly controlled [18], therefore in our country, hypertension is a public health problem. 
The strength of this study is that it is a multi-center study with Colombian representative populations; it provides the first evidence of the effectiveness of olmesartan and amlodipine in daily clinical practice in our country.

\section{Conclusion}

In this study of daily clinical practice in Colombian patients, the FDC of olmesartan/amlodipine provides excellent systolic and diastolic blood pressure control. More than $63 \%$ of patients achieved their blood pressure goal-reduced pulse pressure of $13 \mathrm{mmHg}$-and the medication combination is well tolerated.

\section{Abbreviations}

SBP: systolic blood pressure; DBP: diastolic blood pressure; BP: blood pressure; FDC: combination in fixed doses; PP: pulse pressure

\section{Authors' contributions}

RB participated in the design, acquisition, and analysis of data. MZ participated in the interpretation of the data, as well as the drafting and revision of the manuscript. Both authors read and approved the final manuscript.

\section{Author details}

${ }^{1}$ Colsubsidio Centro de Especialistas, Pontificia Universidad Javeriana, Hospital de la Policía, Bogotá, D.C., Colombia. ${ }^{2}$ Colsubsidio Centro de Especialistas, Pontificia Universidad Javeriana, Hospital de la Samaritana, Bogotá, D.C., Colombia.

\section{Acknowledgements}

The authors would like to acknowledge Tecnofarma for the support to carry out this study.

Bernoulli Gallego, Luis Vargas, Hugo Botero, Carlos Estruch.

Writing assistance: Leonardo David Ospino Vera.

Physicians' enrolled patients: Juan Acosta Ossio, Adela Carmona, Jorge Aguilera, Oscar Alba, Juan Guilermo Alvarez, Jorge Angel, Roberto Arbelaez, Fredy Arcila, Fernando Barrera, Ronald Briceño, Hugo Bustamante, Carlos Daza, Carlos Carvajal, Aura Maria Cuellar, Pablo Duran, Maria Echavarria, Eduardo Fajardo, Osiris Garcia, Fernando Garcia, Fulgencio Garcia, Julio Giraldo, Adriana Gomez, Nasly Granada, Juan Carlos Guerrero, Marisela Hernandez, Andres Jacome, Nicolas Jaramillo, William Jaramillo, Juan Maestre, Edwin Klinger, Germán Lopez, Carlos Luengas, Andres Martinez, Gabriel Martinez, Hassan Matar Khalil, Augusto Melendez, Antonio Mora, Alexander Morales, Juan Moreno, Andres Moreno, Luis Murillo, Martha Narvaez, Juan Palacio, Jorge Peñaloza, Miguel Perdomo, Luis Plata, Jerson Quitian, Marco Tulio Ramirez, Ivan Dario Ramirez, Jorge Restrepo, Efraín Romero, Roberto Exposito, Gabriel Robledo, Yuri Sabogal, Jorge Salcedo, Pedro Sanchez, Marco Sanchez, Milton Sanchez, Miguel Sevillano, Guillermo Sierra, Luis Sterling, Jose Torrenegra, Leisman Ustariz Navarro, Ana Catalina Vanegas, Manuel Vela, Cesar Vera, Juan Carlos Vidal, Juan Carlos Villabona, Italo Zuñiga.

\section{Competing interests}

The authors declare that they have not received any payment or resources for the realization of this study. Richard Buendia claims to be a speaker for different laboratories in Colombia; he has also acted as an external medical consultant on the cardiovascular line Tecnofarma, but has not received payment for carrying out this study. All authors declare that they have no actual or potential conflict of interest, including any financial, personal, or other relationships with related people or organizations.

\section{Availability of data and materials}

Raw data from this study will be available for researchers/implementers upon request from the first author $(\mathrm{RB})$.

\section{Consent to participate}

All authors agree to submit this study to the BMC Research Notes Journal.
Ethics approval and consent to participate

This study is retrospective; data were collected only from medical records. All patients, however, filled out the informed consent form.

Under Colombian law ("Resolución 8430 de 1993"), this study is considered safe because there has been no intervention or intentional modification of biological, physiological, psychological, or social variables of the individuals participating in the study.

The study was conducted according to the Good Clinical Practice guidelines and the Declaration of Helsinki.

\section{Funding}

The authors declare that they have not received any payment or resources for the realization of this study.

\section{Publisher's Note}

Springer Nature remains neutral with regard to jurisdictional claims in published maps and institutional affiliations.

Received: 22 June 2016 Accepted: 18 April 2017

Published online: 26 April 2017

\section{References}

1. Ong KL, Cheung BM, Man YB, Lau CP, Lam KS. Prevalence, awareness, treatment, and control of hypertension among United States adults 1999-2004. Hypertension. 2007;49(1):69-75.

2. Wolf-Maier K, Cooper RS, Banegas JR, Giampaoli S, Hense HW, et al. Hypertension prevalence and blood pressure levels in 6 European countries, Canada, and the United States. JAMA. 2003;289(18):2363-9.

3. Smith $\mathrm{DH}$. Comparison of angiotensin II type 1 receptor antagonists in the treatment of essential hypertension. Drugs. 2008;68(9):1207-25.

4. Lopez-Candales A. Importance of the Hispanic heritage regarding diagnosis and management of hypertension. Postgrad Med. 2015:127(6):571-2.

5. Sorlie PD, Allison MA, Aviles-Santa ML, Cai J, Daviglus ML, et al. Prevalence of hypertension, awareness, treatment, and control in the Hispanic Community Health Study/Study of Latinos. Am J Hypertens. 2014:27(6):793-800.

6. James PA, Oparil S, Carter BL, Cushman WC, Dennison-Himmelfarb C, et al. 2014 evidence-based guideline for the management of high blood pressure in adults: report from the panel members appointed to the Eighth Joint National Committee (JNC 8). JAMA. 2014;311(5):507-20.

7. Chrysant SG, Melino M, Karki S, Lee J, Heyrman R. The combination of olmesartan medoxomil and amlodipine besylate in controlling high blood pressure: $\mathrm{COACH}$, a randomized, double-blind, placebo-controlled, 8-week factorial efficacy and safety study. Clin Ther. 2008;30(4):587-604.

8. Volpe M, Brommer P, Haag U, Miele C. Efficacy and tolerability of olmesartan medoxomil combined with amlodipine in patients with moderate to severe hypertension after amlodipine monotherapy: a randomized, double-blind, parallel-group, multicentre study. Clin Drug Investig. 2009;29(1):11-25.

9. Weir MR, Hsueh WA, Nesbitt SD, Littlejohn TJ 3rd, Graff A, et al. A titrateto-goal study of switching patients uncontrolled on antihypertensive monotherapy to fixed-dose combinations of amlodipine and olmesartan medoxomil \pm hydrochlorothiazide. J Clin Hypertens. 2011;13(6):404-12.

10. Rosero-Bixby L, Coto-Yglesias F, Dow WH. Pulse blood pressure and cardiovascular mortality in a population-based cohort of elderly Costa Ricans. J Hum Hypertens. 2015;30:555-62.

11. Borrell $L N$, Samuel $L$. The effect of pulse pressure on all-cause and cardiovascular-specific mortality risks in US adults. Ethn Dis. 2015;25(2):152-6.

12. Zhao L, Song Y, Dong $P$, Li Z, Yang $X$, et al. Brachial pulse pressure and cardiovascular or all-cause mortality in the general population: a meta-analysis of prospective observational studies. J Clin Hypertens. 2014;16(9):678-85.

13. Furberg C, Wright T, Davis B, et al. Lipid-Lowering Treatment to Prevent Heart AttackT. Major outcomes in high-risk hypertensive patients randomized to angiotensin-converting enzyme inhibitor or calcium channel blocker vs diuretic: the antihypertensive and lipid-lowering treatment to prevent heart attack trial (ALLHAT). JAMA. 2002;288(23):2981-97. 
14. Dolor RJ, Yancy WS Jr, Owen WF, Matchar DB, Samsa GP, et al. Hypertension improvement project (HIP): study protocol and implementation challenges. Trials. 2009;10:13.

15. SHEP Cooperative Research Group. Prevention of stroke by antihypertensive drug treatment in older persons with isolated systolic hypertension. Final results of the systolic hypertension in the elderly program (SHEP). JAMA. 1991;265(24):3255-64.

16. Mancia G, Laurent S, Agabiti-Rosei E, Ambrosioni E, Burnier M, et al. Reappraisal of European guidelines on hypertension management: a European Society of Hypertension Task Force document. Blood Press. 2009;18(6):308-47.
17. Mancia G, Fagard R, Narkiewicz K, et al. Practice guidelines for the management of arterial hypertension of the European Society of Hypertension (ESH) and the European Society of Cardiology (ESC): ESH/ESC Task Force for the Management of Arterial Hypertension. J Hypertens. 2013;31(10):1925-38.

18. Valencia J, Orozco J. Cost-effectiveness renal denervation therapy vs. the best standard medical treatment available in the control of resistant hypertension in Colombia. Rev Colomb Cardiol. 2014;21(3):142-51.

\section{Submit your next manuscript to BioMed Central and we will help you at every step:}

- We accept pre-submission inquiries

- Our selector tool helps you to find the most relevant journal

- We provide round the clock customer support

- Convenient online submission

- Thorough peer review

- Inclusion in PubMed and all major indexing services

- Maximum visibility for your research

Submit your manuscript at

www.biomedcentral com/submit 